\title{
Effect of Acetate Group Content in Ethylene-Vinyl Acetate Copolymer on Properties of Composite Based on Low Density Polyethylene and Polyamide-6
}

\author{
Nhi Dinh Bui, ${ }^{1}$ Ngo Dinh Vu, ${ }^{1}$ Thao Thi Minh, ${ }^{1}$ Huong Thi Thanh Dam, \\ Regina Romanovna Spiridonova, ${ }^{2}$ and Semenovich Alexandr Sirotkin ${ }^{3}$ \\ ${ }^{1}$ Faculty of Environmental Technology, Viet Tri University of Industry, Tien Kien, Lam Thao, Phu Tho, Vietnam, Vietnam \\ ${ }^{2}$ Faculty of Biotechnology, Institute of Polymer of Kazan National Research Technological University, 68 Karla Marksa Street, \\ Kazan, Republic of Tatarstan 420015, Russia \\ ${ }^{3}$ Faculty of Biotechnology, Institute of Food Engineering and Biotechnology of Kazan National Research Technological University, \\ 68 Karla Marksa Street, Kazan, Republic of Tatarstan 420015, Russia
}

Correspondence should be addressed to Nhi Dinh Bui; vietnamkz@yahoo.com

Received 18 February 2016; Revised 8 April 2016; Accepted 3 May 2016

Academic Editor: Cornelia Vasile

Copyright (C) 2016 Nhi Dinh Bui et al. This is an open access article distributed under the Creative Commons Attribution License, which permits unrestricted use, distribution, and reproduction in any medium, provided the original work is properly cited.

\begin{abstract}
The effect of the content of vinyl acetate groups in ethylene-vinyl acetate copolymer on the properties of polymer composite based on low density polyethylene and polyamide- 6 was studied. Ethylene-vinyl acetate copolymer containing less vinyl acetate groups (10-14 wt.\%) has a positive compatibility effect on polymer composite than ethylene-vinyl acetate copolymer containing $21-30 \mathrm{wt} . \%$ vinyl acetate groups. The polymer composites of LDPE, PA-6, and EVA containing 10-14 wt.\% vinyl acetate groups possess the ability of biodegradation. The physical-mechanical properties of sample and molecular mass reduce after 28 days of incubation.
\end{abstract}

\section{Introduction}

Plastic packaging has come to occupy an indispensable place in human life. It is difficult to imagine that at the beginning of the last century plastic products did not yet exist. The successful development of polymer packaging materials for long-term food storage has made conditional that they are a functional, lightweight, strong, cheap, and hygienic way to transport food. A substantial growth in the consumption of plastic packaging materials is contributed to a concern, the proper disposal of waste plastics. All over the world the packaging science is constantly looking for new ways to reduce packaging waste. Plastics in food packaging after using go to landfill. They make up $10-12 \%$ of total waste in landfills. Of these, polyethylene (PE) makes up about 38\%, polyvinylchloride and its derivatives $15 \%$, polypropylene $8 \%$, and other plastics 39\%. The time required for decomposition of such polymer materials under natural conditions is 20 to 300 years depending on type and the sizes of waste [1-3].
From the point of view of environmental safety and economic benefit, a mixture of nonbiodegradable synthetic polymers with a biodegradable polymer producing environmentally friendly polymers is an established technique to solve this problem [4]. On the other hand, it was found that it is sometimes more desirable to mix polymers to combine several properties from each homopolymer of the blend [5]. So most pairs of polymers are immiscible, when mixed together they form a two-phase. Weak physical or chemical interactions between the phases of the mixture are usually the cause of poor properties of blends. Improving the compatibility of the mixture is one of the main objectives of creation of polymeric compositions. Increasing interfacial adhesion between the phases is achieved by compatibilization through the introduction of physical or/and chemical interaction between the components $[6,7]$.

In previous works [8-10] showed that ethylene-vinyl acetate copolymer (EVA) was used as compatibilizer to overcome the incompatibility for blend of low density 
polyethylene (LDPE) and polyamide (PA-6), which is well known as a biodegradable polymer [11-13]. However, in these works the effect of the content of vinyl acetate groups on the properties of polymer composition was not studied. Addressing this issue is consecrated to our research.

\section{Experimental}

\subsection{Materials}

The following materials were used.

(i) Low density polyethylene (LDPE) ( $\rho 930 \mathrm{~kg} / \mathrm{m}^{3}$ and melting temperature $110^{\circ} \mathrm{C}$, provided by "OJS Company Kazanorgsintez," Russia).

(ii) polyamide-6 (PA-6) ( $\rho 1155 \mathrm{~kg} / \mathrm{m}^{3}$ and melting temperature $225^{\circ} \mathrm{C}$, obtained by anion polymerization of $\varepsilon$-caprolactam and provided by JSC "Metafrax," Russia),

(iii) EVA type I (containing vinyl acetate groups 1014 wt.\%, $\rho 933 \mathrm{~kg} / \mathrm{m}^{3}$, and melt flow index (MFI) $\left(190^{\circ} \mathrm{C}\right)$ 5.0-10 g/10 min, provided by "OJS Company Kazanorgsintez," Russia).

(iv) EVA type II (containing vinyl acetate groups 21-30 wt.\%, $\rho 942 \mathrm{~kg} / \mathrm{m}^{3}$, and MFI $\left(190^{\circ} \mathrm{C}\right) 3.0-$ $5.5 \mathrm{~g} / 10 \mathrm{~min}$, provided by "OJS Company Kazanorgsintez," Russia).

Irgafos 168 (Tris(2,4-di-tert-butylphenyl) phosphate) (Ciba, Switzerland) and Agidol 40 (2,4,6-Tris(3,5-di-tert-butyI-4hydroxybenzyl) Mesitylene) [14] were used as thermostabilizer.

2.2. Blends Preparation. The composites were prepared by rotary mixer (Brabender ${ }^{\circledR}$ EC plus, Germany) under nitrogen for $5 \mathrm{~min}$ at $200^{\circ} \mathrm{C}$. The rotor speed was $50 \mathrm{rpm}$. Ratio of components in a mixture was changed: PE (80-100 wt.\%), PA (от $0-10$ wt.\%), and EVA (0-10 wt.\%).

2.3. Biodegradability Testing. Biodegradability evaluation of received blends was performed on solid media Czapek using mixed fungal culture. Antifungal performance is tested according to ASTM G21-96 (Standard Practice for Determining Resistance of Synthetic Polymeric). Prepare medium Czapek by dissolving in $1 \mathrm{~L}$ of water the designated amounts of the following reagents: saccharose $30 \mathrm{~g}, \mathrm{NaNO}_{3} 3 \mathrm{~g}, \mathrm{KH}_{2} \mathrm{PO}_{4}$ $1 \mathrm{~g}, \mathrm{MgSO}_{4} \times 7 \mathrm{H}_{2} \mathrm{O} 0.5 \mathrm{~g}, \mathrm{KCl} 0.5 \mathrm{~g}, \mathrm{FeSO}_{4} \times 7 \mathrm{H}_{2} \mathrm{O} 0.01 \mathrm{~g}$, and agar $15 г$. Film of polymer composite $(50 \times 50 \mathrm{~mm}$ with thickness of $0.2 \mathrm{~mm}$ ) and media Czapek were sterilized at $0.5 \mathrm{~atm}$ of steam for $30 \mathrm{~min}$. Samples were placed in a Petri dish on the surface of solid media under sterilized conditions and then the mixed fungal cultures were carried out using microbial loop. Plates were incubated at $28^{\circ} \mathrm{C}$ for 28 days.

\subsection{Blends Characterizations}

2.4.1. Mechanical Properties. The mechanical properties, namely, elongation at break $(\varepsilon)$ and tensile strength at break $(\sigma)$, were measured using universal testing machine Inspekt mini $3 \mathrm{kN}$ (Trilogica, Germany) at $20^{\circ} \mathrm{C}$. The samples were cut out of compression-molded films. The films were $1.0 \mathrm{~mm}$ thick in accordance with GOST 12019-66.

2.4.2. Rheological Properties. Melt flow index (MFI) was determined by capillary viscometer IIRT-5 M (Russia). The diameter of a capillary is $0.2095 \pm 0.0005 \mathrm{~cm}$. MFI was measured following the method of standard test ASTM D 1238 at the temperature of $190^{\circ} \mathrm{C}$ and the load of $2.16 \mathrm{~kg}$.

2.4.3. FTIR Analysis. The chemical structure of the polymer compositions can be evaluated using the FTIR spectroscopy «InfraLIOM FT-08》. After the FTIR analysis LDPE/PA6/EVA blend samples were purified using formic acid and hot orthoxylene as selective solvents. Blend samples were treated first with formic acid, and the insoluble fraction was separated by centrifugation of the suspensions, washed with the pure methanol, and dried to constant weight. The dried sample was extracted further by repeated treatments with hot orthoxylene to obtain orthoxylene soluble and orthoxylene insoluble fraction. The soluble and insoluble fractions were washed several times with pure acetone and then dried to constant weight. The dried insoluble products were used for measuring molecular weight. The purified insoluble products of LDPE functionalized and obtained blends were compression molded in thin films with a thickness of about $0.05 \mathrm{~mm}$ for FTIR analysis.

2.4.4. Morphological Analysis. The surface chemical composition of polymers was studied by using intermittent-contact atomic force microscopy (IC-AFM) MultiMode V (Veeco) and the optical microscope VH-Z500R (Keyence Co., Japan).

2.4.5. Thermal Analysis. Differential scanning calorimetric (DSC) analysis was performed under nitrogen flow, at a scanning rate of $5^{\circ} \mathrm{C} / \mathrm{min}$ using a DSC 1 STARe (Mettler Toledo, USA).

Thermal stability of composites was evaluated using thermogravimetric analysis (TGA) on the instrument STA 6000 (PerkinElmer, USA) with the relaxation character at a heating rate $5^{\circ} \mathrm{C} / \mathrm{min}$ up to $500^{\circ} \mathrm{C}$.

2.4.6. Thermomechanical Analysis. Thermomechanical analysis (TMA) samples was done using TMA 402F (NetzschGeratebau GmbH, Germany). The experiment was carried out under nitrogen flow at a heating rate of $5^{\circ} \mathrm{C} / \mathrm{min}$. Heat resistance was evaluated softening temperature, which is determined by the response curves change of linear dimensions of the sample (\%) versus temperature.

2.5. Assessment of Biodegradation. The evaluations of the fungus resistance were performed by the growth intensity of fungus on the polymer film surface placed on solid media Czapek and were according to a 5-point scale ranging from zero to $100 \%$ fungal growth. Before being placed on solid culture medium, the polymer films were cut in size $5 \times 7 \mathrm{~cm}$ 


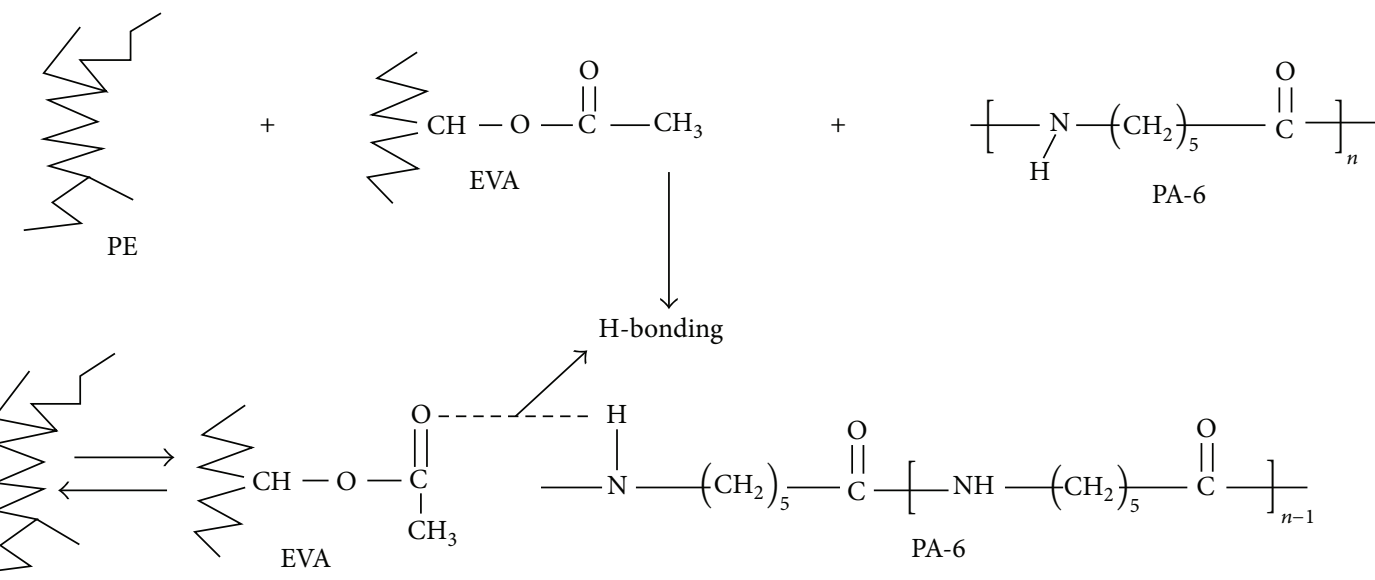

PE

Scheme 1: Possible chemical reactions between PE, PA-6, and EVA.

or $5 \times 5 \mathrm{~cm}$ with thickness $0.2 \pm 0.02 \mathrm{~mm}$ and washed with alcohol and then with distilled water.

The sample surface after biodegradation was studied by using atomic force microscopy (AFM). The microscopic studies on the morphology were conducted using phase contrast microscope (Leica DM 750) with the highest power objective lenses (i.e., 100x lens).

The physical-mechanical properties (elongation at break $(\varepsilon)$ and tensile strength at break $(\sigma)$ ) of the samples after degradation by microorganisms were measured using universal testing machine Inspekt mini $3 \mathrm{kN}$ (Trilogica, Germany) at $20^{\circ} \mathrm{C}$.

Viscosity average molecular weight $(\mathrm{Mv})$ was determined by using an Ubbelohde capillary viscometer. The dried soluble samples were dissolved in orthoxylene in the range from 0.2 to $0.4 \mathrm{~g} / \mathrm{dL}$.

\section{Results and Discussion}

During the melt extrusion of recycled polymer blend (LDPE/PA-6) with EVA, the possible chemical interaction (H-bonding) can be expected between amine end groups (-NH) of PA-6 component and vinyl acetate groups of EVA. At the same time, a specific intermolecular interaction between polyethylene segments of EVA and those of the $\mathrm{PE}$ may also occur. The possible interactions between the polymer components of blend are proposed in Scheme 1 [10].

Polymeric composite containing 10 wt.\% PA-6 has low physical-mechanical properties as compared with the control LDPE (Figures 1(a) and 1(b)). At the same time, MFI of the sample is reduced by four times (Figure 1(c)). It is due to the low thermal stability of the PA-6 and, as a consequence, degradation leading to cross-linking of matrix polymer.

As seen in Figure 1, the content of vinyl acetate groups in EVA has significant effect on properties of the polymer composite. The introduction of even $1 \mathrm{wt}$.\% EVA type II to polymer blend leads to forming fully cross-linked composite that cannot processed by any methods. Physical-mechanical properties remain at the level of the polymer composite without compatibilizer. At the same time, the melting viscosity of composites, containing EVA type $\mathrm{I}$, is reduced.
Physical-mechanical properties also increase. However, their values do not reach the control properties of LDPE.

Using stabilizer is a way to enhance degradation resistance of the polymer composition at high temperatures of processing. The previous research showed that the mixture of stabilizers of Agidol 40 and Irgafos 168 is the most effective stabilizer for a polymer composite based on LDPE and PA-6 [15].

The influence of type of EVA on properties of polymer composites based on LDPE and PA- 6 in presence of a mixture of stabilizers of 0.1 wt.\% of Agidol 40 and 0.1 wt.\% Irgafos 168 is presented in Table 1.

As a result of using stabilizer the melting viscosity of the studied composites significantly reduced (Table 1). The more composite contains EVA, the lower it has the viscosity. Decrease in molecular weight of polymer during processing can be the reason of increase in MFI or decrease in the melting viscosity. Possibly, stabilizers change (alter) the mechanism of interaction with the free formed radicals during destruction. Without using stabilizers radicals interact with defective areas in macromolecule of LDPE and sew them. At the same time, presence of Agidol 40 and Irgafos 168 stabilize the polymer chain broken off during destruction. However, physical-mechanical properties of composites increase. It indicates an increase of physical and chemical interactions between the phases of the polymer mixture.

Thus, EVA containing less vinyl acetate groups 10-14 wt.\% (type I) in the presence of a mixture of stabilizers Irgafos 168 and Agidol 40 has a positive compatibility effect on polymer composite than ethylene-vinyl acetate copolymer containing 21-30 wt.\% vinyl acetate groups (type II).

Quantification of surface morphology of the samples was performed using IC-AFM (Figure 2). Comparison AFM images show that the samples containing PA-6 have a high surface roughness when compared to the initial LDPE. Using the EVA type 1 reduces the surface roughness from $410 \mathrm{~nm}$ to $180 \mathrm{~nm}$. As a result PA-6 was uniform distribution in the matrix of LDPE.

IR spectrum of purified sample LDPE/PA-6/EVA, in addition to the absorption bands for LDPE, shows the absorption bands of PA- 6 segments at $1638 \mathrm{~cm}^{-1}$ - stretching 
TABLE 1: Influence of type of EVA on properties of polymer composite based on LDPE and PA-6 in presence of a mixture of stabilizers of 0.1 wt.\% of Agidol 40 and 0.1 wt.\% Irgafos 168.

\begin{tabular}{|c|c|c|c|c|c|c|}
\hline \multirow{3}{*}{ LDPE } & \multicolumn{3}{|c|}{ Relative content component of blend, wt.\% } & \multirow{3}{*}{ MFI (g/10 min) } & \multirow{3}{*}{$\varepsilon(\%)$} & \multirow{3}{*}{$\sigma(\mathrm{MPa})$} \\
\hline & \multirow{2}{*}{ PA-6 } & \multicolumn{2}{|c|}{ EVA } & & & \\
\hline & & Type I & Type II & & & \\
\hline 100 & 0 & 0 & 0 & 0.20 & 905 & 17 \\
\hline 90 & 10 & 0 & 0 & 0.29 & 703 & 11 \\
\hline 89 & 10 & 1 & 0 & 0.35 & 830 & 16 \\
\hline 85 & 10 & 5 & 0 & 0.36 & 865 & 16 \\
\hline 80 & 10 & 10 & 0 & 0.38 & 570 & 15 \\
\hline 89 & 10 & 0 & 1 & 0.20 & 650 & 12 \\
\hline 85 & 10 & 0 & 5 & 0.24 & 720 & 13 \\
\hline 80 & 10 & 0 & 10 & 0.29 & 560 & 10 \\
\hline
\end{tabular}

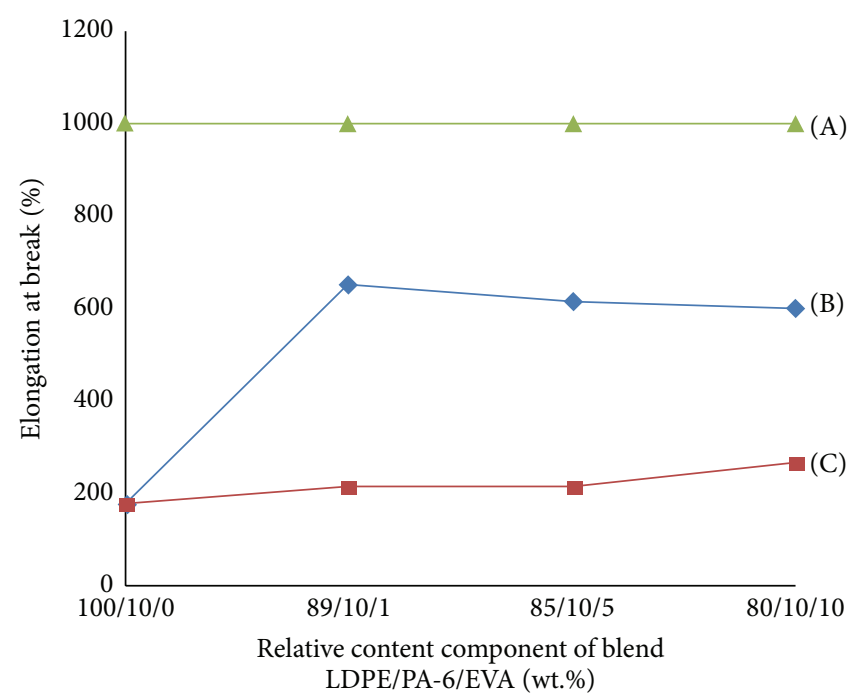

(a)

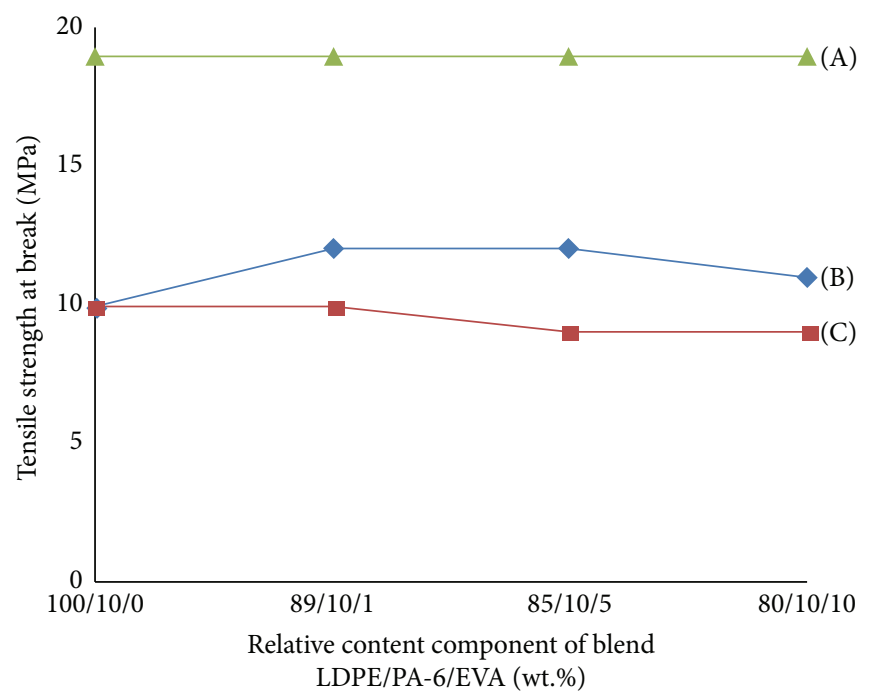

(b)

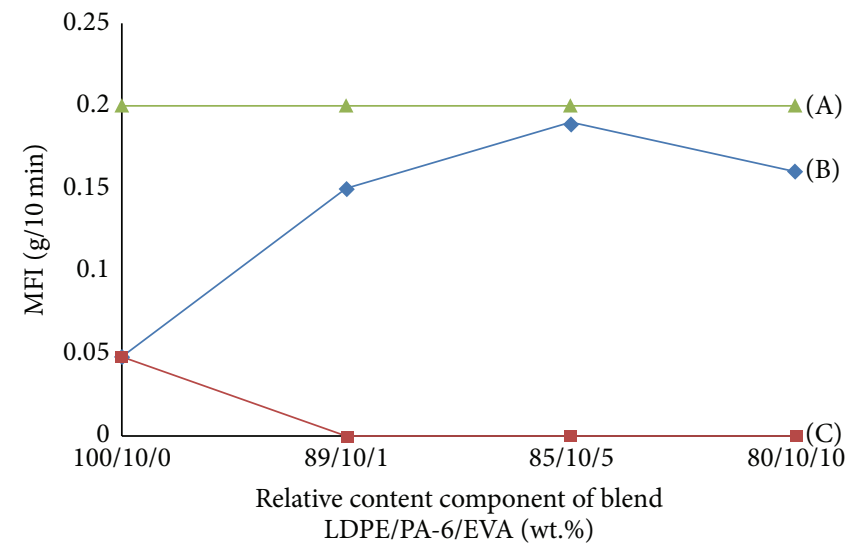

(c)

FIGURE 1: Estimation of the effect of different types EVA on the properties of the polymer composite of LDPE and PA-6: (A) control sample (LDPE); (B) polymer composite, containing EVA type I; (C) polymer composite, containing EVA type II. 

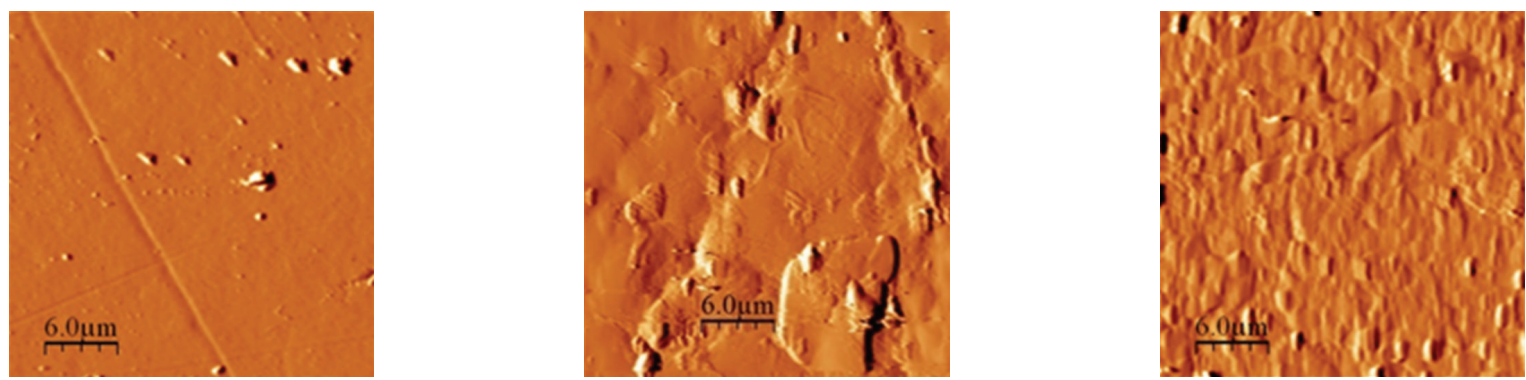

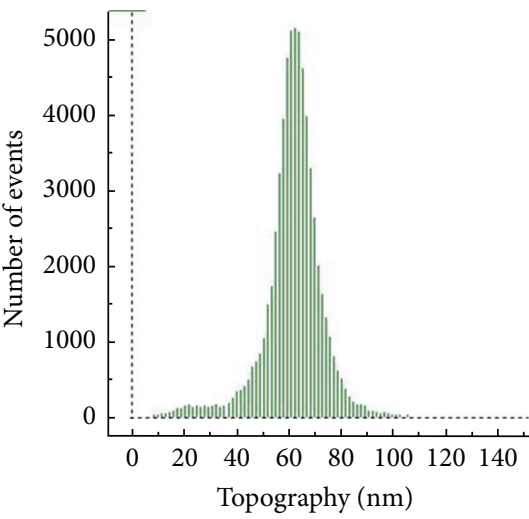

(a)

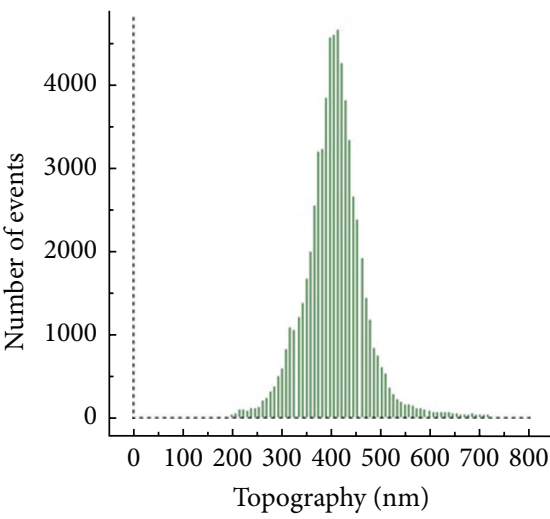

(b)

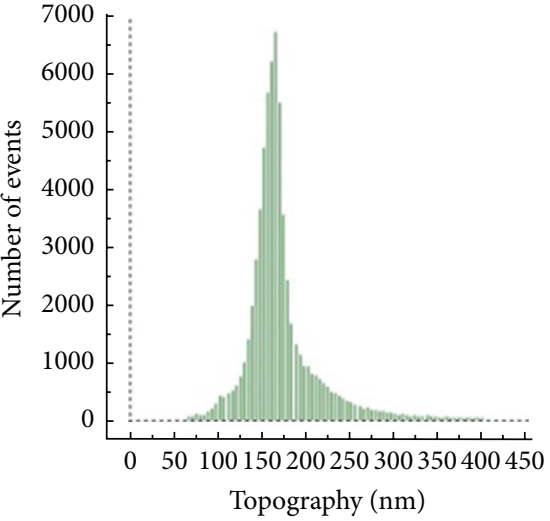

(c)

Figure 2: AFM images of the surface of polymer composites: (a) the source of LDPE, (b) 90 wt.\% LDPE/10 wt.\% PA-6, (c) 90 wt.\% LDPE/10 wt.\% PA-6/1 wt.\% EVA type I/0.1 wt.\% Agidol-40/0.1 wt.\% Irgafos-168.

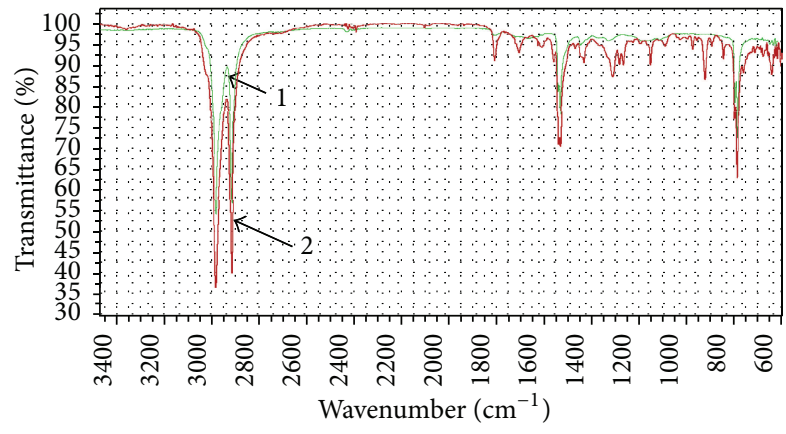

FIGURE 3: The IR spectra of initial LDPE (1) and received composite containing 85 wt.\% LDPE/10 wt.\% PA-6/5 wt.\% EVA type I (2).

vibrations of the $\mathrm{C}=\mathrm{O}$ groups, $1544 \mathrm{~cm}^{-1}$ and $3297 \mathrm{~cm}^{-1}$, deformation and stretching vibrations of $\mathrm{NH}$-groups, respectively (Figure 3). However, in the spectrum of the polymer composite two bands at $1244 \mathrm{~cm}^{-1}$ and $610 \mathrm{~cm}^{-1}$ are assigned to the asymmetric and symmetric stretching of the carbonyl bond $(\mathrm{C}=\mathrm{O})$ of the grafted EVA.

The ability of the polymer product can maintain performance at elevated temperatures and is determined by heat resistance which characterizes the upper limit of operating temperatures. Figure 4 shows the TGA curves for the pure polymers and their composites. The presence of stabilizers in the polymer blend composite leads to increase their thermal stability and reduce the degradation rate compared with the pure polymers.
TABLE 2: Effect of the content of PA- 6 and EVA-113 on melting point $\left(T_{m}\right)$, softening point $\left(T_{s}\right)$, and degree of crystallinity $(\chi)$ of pure LDPE and its composites containing $0.1 \mathrm{wt}$.\% Agidol-40 and $0.1 \mathrm{wt} . \%$ Irgafos-168.

\begin{tabular}{lccc}
\hline $\begin{array}{l}\text { Content and component } \\
\text { composition LDPE/PA 6/EVA } \\
\text { type 1 (wt.\%) }\end{array}$ & $T_{m},{ }^{\circ} \mathrm{C}$ & $T_{s},{ }^{\circ} \mathrm{C}$ & $\chi, \%$ \\
\hline $100 / 0 / 0$ & 111 & 105 & 59 \\
$89 / 10 / 1$ & 110 & 105 & 55 \\
$85 / 10 / 5$ & 110 & 106 & 54 \\
$80 / 10 / 10$ & 113 & 104 & 49 \\
\hline
\end{tabular}

As shown in Table 2, introduction of PA-6 (to $10 \mathrm{wt} . \%$ ), EVA type 1, and in the presence of the mixture stabilizers with no effect on the melting and softening points of composite, the degree of crystallinity decreases.

Thus, EVA containing 10-14 wt.\% of vinyl acetate groups and in presence of the mixture of stabilizers of Agidol 40 and Irgafos 168 has a positive compatibility effect on polymer composite based on LDPE and PA-6 as compared to EVA containing 21-30 wt.\% vinyl acetate groups.

Polymer composites of LDPE, PA-6, and EVA type I were analyzed for their ability of biodegradation. Results of a visual assessment of development of micromycetes for 28 days of incubation show that the surfaces of the polymer composites were overgrown by microscopic fungi, while the 


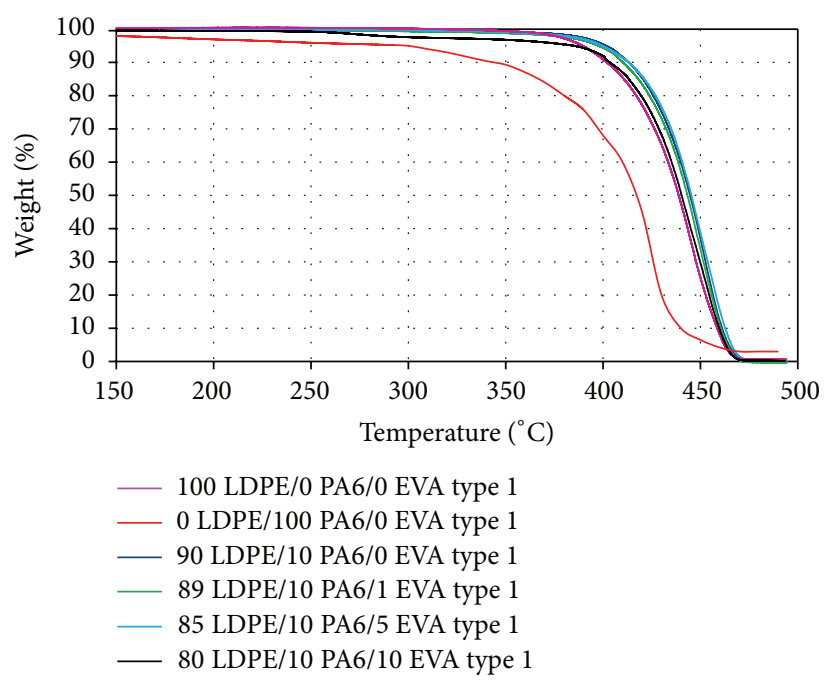

FIgURE 4: TGA curves of polymer composites LDPE/PA 6/EVA type 1 (wt.\%).

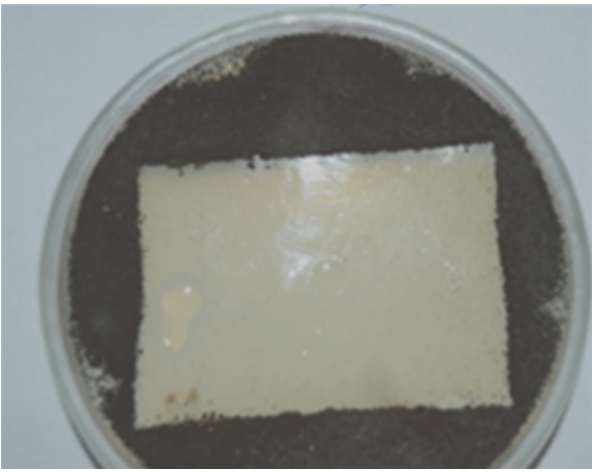

(a)

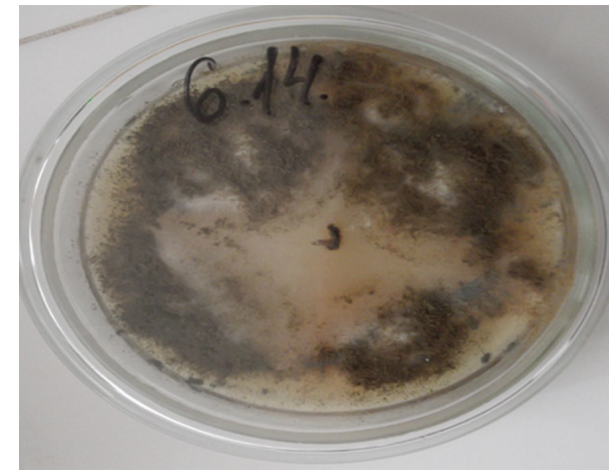

(b)

FIGURE 5: Photograph of LDPE (a) and polymer composition (wt.\%) LPPE (89\%), PA-6 (10\%), and EVA type I (1\%) (b), after biodegradation for $28 \mathrm{~d}$ on solid media Czapek.

control sample LDPE is a zone of "alienation" with the growth of micromycetes on a nutrient medium (Figure 5).

The studied samples had signs of biological damage already in the initial stage of research, after 7 days (Table 3). Blend, containing $10 \mathrm{wt} . \%$ of PA- 6 and $1 \mathrm{wt} . \%$ of EVA, is most susceptible to biodegradation: on the surface of sample 30$60 \%$ of the coating covered by fungal growth after 28 days of incubation. The control LDPE has no sign to biodegradation over the time of incubation.

The micrographs in Figure 6 illustrate the change of the film surface of polymer composition after biodegradation for 28 days. As can be seen in figure, it is the absence of PA-6 in consisting of blend on the surface after biodegradation, which may be associated with its consumption of microbes as source of nutrients.

As a result of biodegradation, the physical-mechanical properties of the samples decrease (Table 4). It might be explained by the fact that the action of microorganisms tends to loosen the polymer structure. Reduction in Mv directly demonstrates the ability of the polymer composite to degrade the conditions of biological aging.
TABLE 3: Assessment of biodeterioration of polymer blends for various incubation times where 0 point: lack of microorganisms on the surface of sample; 1 point: traces of microorganisms (less than $10 \%$ of the coating covered by fungal growth); 2 points: insignificant growth ( $10 \%$ to $30 \%$ of the coating covered by fungal growth); 3 points: significant growth of microbial colonies $(30-60 \%$ of the coating covered by fungal growth).

\begin{tabular}{lccc}
\hline \multirow{2}{*}{ Sample, wt.\% } & \multicolumn{3}{c}{ Fungus resistance, point } \\
& 7 days & 14 days & 28 days \\
\hline 100 LDPE & 0 & 0 & 0 \\
90 LDPE + 10 PA-6 & 1 & 1 & 2 \\
89 LDPE + 10 PA-6 + 1 EVA type I & 1 & 2 & 3 \\
80 LDPE + 10 PA-6 + 10 EVA type I & 1 & 1 & 2 \\
\hline
\end{tabular}

\section{Conclusion}

EVA containing 10-14 wt.\% of vinyl acetate groups has a positive compatibility effect on polymer composites based 
TABLE 4: Some characteristics of polymeric compositions before and after biodegradation for 28 days.

\begin{tabular}{lccccc}
\hline $\begin{array}{l}\text { Samples } \\
\text { LDPE/PA-6/EVA type I (w/w) }\end{array}$ & Before & After & Before & After & \multicolumn{2}{c}{$\begin{array}{c}M_{\eta}, \text { Dalton } \\
\text { Before }\end{array}$} \\
\hline $100 / 0 / 0$ & 790 & 660 & 17 & 16 & 340000 \\
$89 / 10 / 1$ & 544 & 100 & 16 & 14 & 288000 \\
$85 / 10 / 5$ & 540 & 270 & 18 & 15 & 219000 \\
$80 / 10 / 10$ & 500 & 340 & 15 & 14 & 161000 \\
\hline
\end{tabular}

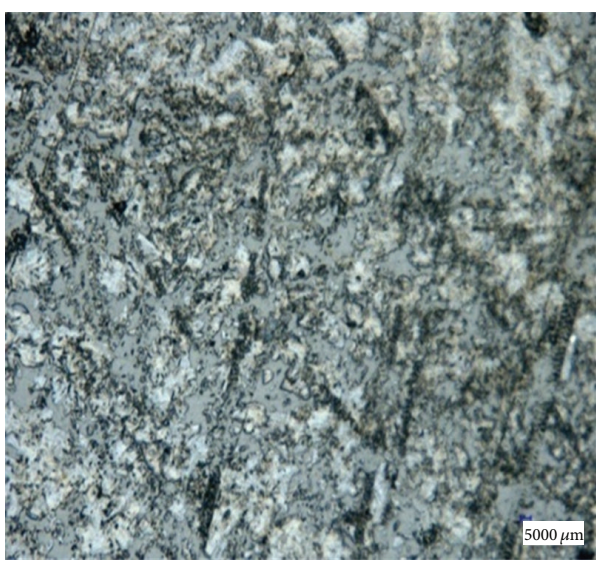

(a)

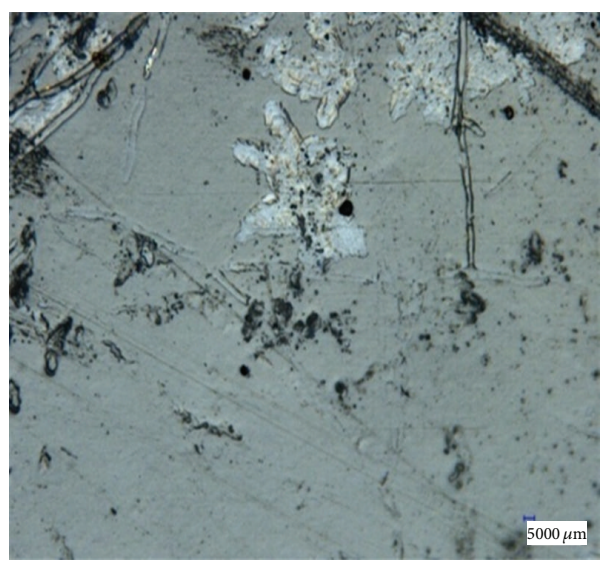

(b)

Figure 6: Micrographs of the film surface of polymer composite LDPE (80 wt.\%), PA-6 (10 wt.\%), and EVA type I (10 wt.10\%) (enlargement 5000x) before biodegradation (a) and after biodegradation for 28 days.

on LDPE and PA-6 as compared to EVA containing 21$30 \mathrm{wt} . \%$ vinyl acetate groups. The mixture of stabilizers of Agidol 40 and Irgafos 168 changes (alter) the mechanism of interactions with the free formed radicals during destruction. As a result of that MFI and physical-mechanical properties of the polymer compositions enhance.

The polymer composites of LDPE, PA-6, and EVA containing 10-14 wt.\% vinyl acetate groups have the ability of biodegradation. It has shown signs of primary biodamage of samples on the 7 th day of the experiment and after 28 of incubation 30 to $60 \%$ of the total area of surface of sample supports the growth of microorganisms. As a result of biodegradation physical-mechanical properties of the samples and their molecular weight reduce.

\section{Competing Interests}

The authors declare that they have no competing interests.

\section{Acknowledgments}

This work was financially supported by the Ministry of Education and Science of the Russian Federation, Contract no 14.V37.21.0838.

\section{References}

[1] O. Legonkova and G. Kudriakov, Tara and Unakovka, vol. 4, p. 18,2010
[2] O. Legonkova, Tara and Unakovka, vol. 1, p. 25, 2008.

[3] B. T. Tarasyuk, Tara and Unakovka, 55, 2011.

[4] I. M. Arcana, B. Bundjali, I. Yudistira, B. Jariah, and L. Sukria, "Study on properties of polymer blends from polypropylene with polycaprolactone and their biodegradability," Polymer Journal, vol. 39, no. 12, pp. 1337-1344, 2007.

[5] A. Valenza, G. Geuskens, and G. Spadaro, "Blends of polyamide 6 and linear low density polyethylene functionalized with methacrylic acid derivatives," European Polymer Journal, vol. 33, no. 6, pp. 957-962, 1997.

[6] L. Minkova, H. Yordanov, and S. Filippi, "Characterization of blends of LDPE and PA6 with functionalized polyethylenes," Polymer, vol. 43, no. 23, pp. 6195-6204, 2002.

[7] R. Scaffaro, F. P. La Mantia, L. Canfora, G. Polacco, S. Filippi, and P. Magagnini, "Reactive compatibilization of PA6/LDPE blends with an ethylene-acrylic acid copolymer and a low molar mass bis-oxazoline," Polymer, vol. 44, no. 22, pp. 6951-6957, 2003.

[8] M. Tademr and H. Yildirim, "Achieving compatibility in blends of low-density polyethylene/polyamide- 6 with addition of ethylene vinyl acetate," Journal of Applied Polymer Science, vol. 82, no. 7, pp. 1748-1754, 2001.

[9] E. F. Silva and B. G. Soares, "Polyethylene/polyamide- 6 blends containing mercapto-modified EVA," Journal of Applied Polymer Science, vol. 60, no. 10, pp. 1687-1694, 1996.

[10] A. Choudhury, M. Mukherjee, and B. Adhikari, "Recycling of polyethylene/nylon 6 based waste oil pouches using compatibilizer," Indian Journal of Chemical Technology, vol. 13, no. 3, pp. 233-241, 2006. 
[11] U. Klun, J. Friedrich, and A. Kržan, "Polyamide-6 fibre degradation by a lignolytic fungus," Polymer Degradation and Stability, vol. 79, no. 1, pp. 99-104, 2003.

[12] M. Sudhakar, C. Priyadarshini, M. Doble, P. S. Murthy, and R. Venkatesan, "Marine bacteria mediated degradation of nylon 66 and 6," International Biodeterioration \& Biodegradation, vol. 60, no. 3, pp. 144-151, 2007.

[13] J. Friedrich, P. Zalar, M. Mohorčič, U. Klun, and A. Kržan, "Ability of fungi to degrade synthetic polymer nylon-6," Chemosphere, vol. 67, no. 10, pp. 2089-2095, 2007.

[14] G. N. Nugumanova, S. V. Bukharov, R. G. Tagasheva et al., "Synthesis of sterically hindered phenolic compounds from indole and its derivatives," Russian Journal of Organic Chemistry, vol. 43, no. 12, pp. 1797-1803, 2007.

[15] T. T. Minh, R. R. Spiridonova, A. V. Ivanova, and A. M. Kochnev, Vestnik of Kazan National Research Technological University, vol. 15, pp. 187-190, 2012. 

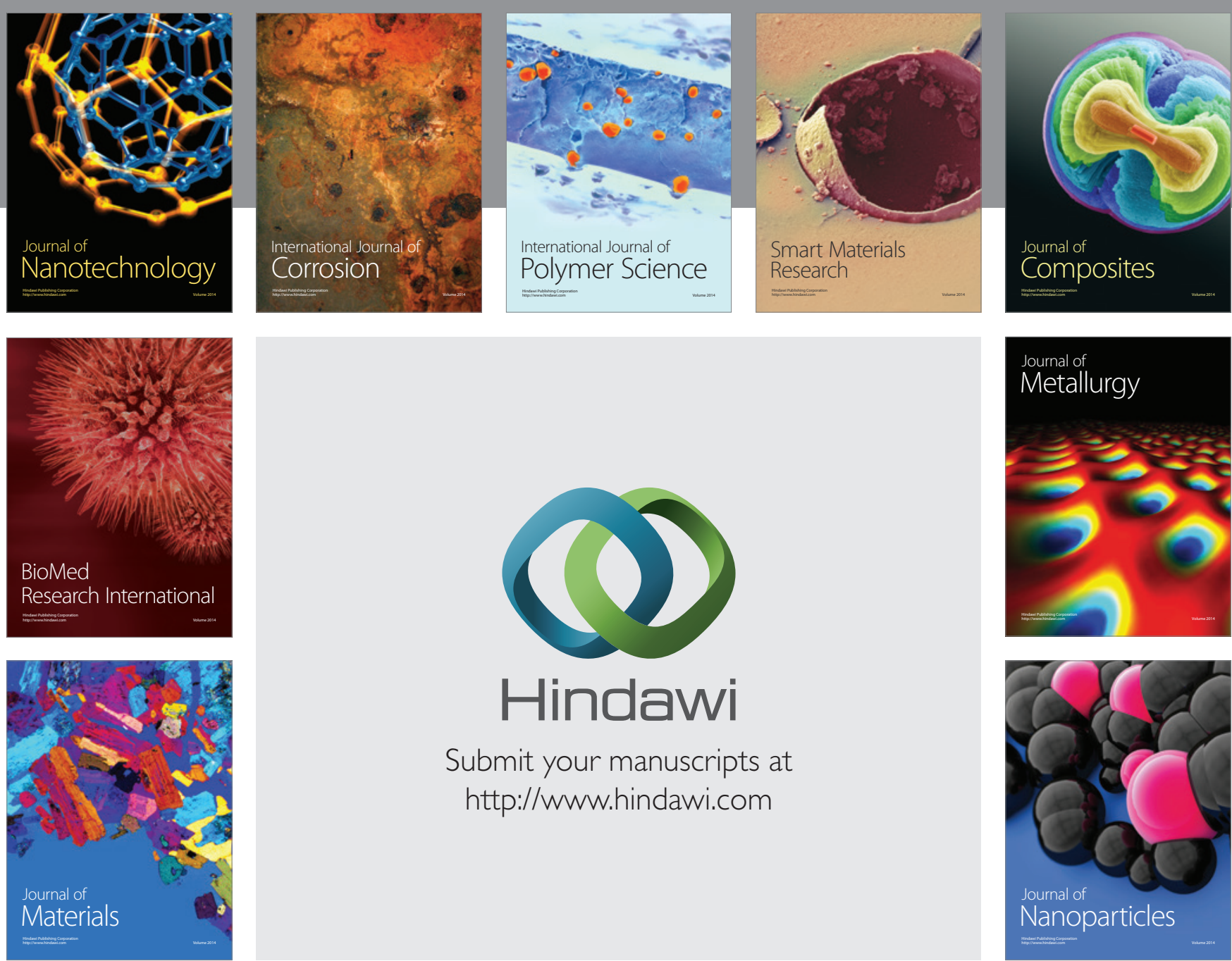

\section{Hindawi}

Submit your manuscripts at

http://www.hindawi.com

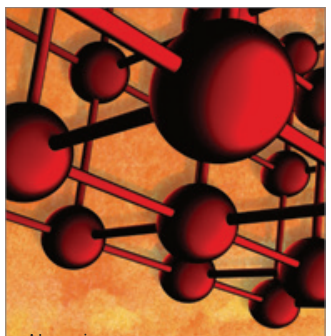

Materials Science and Engineering
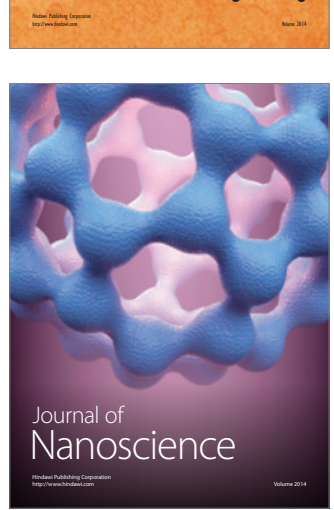
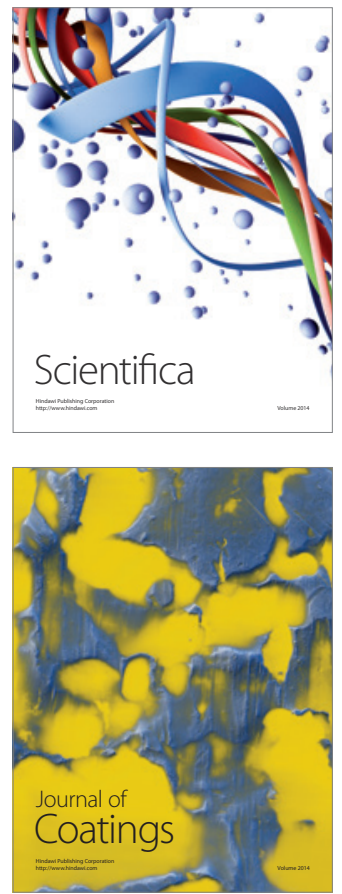
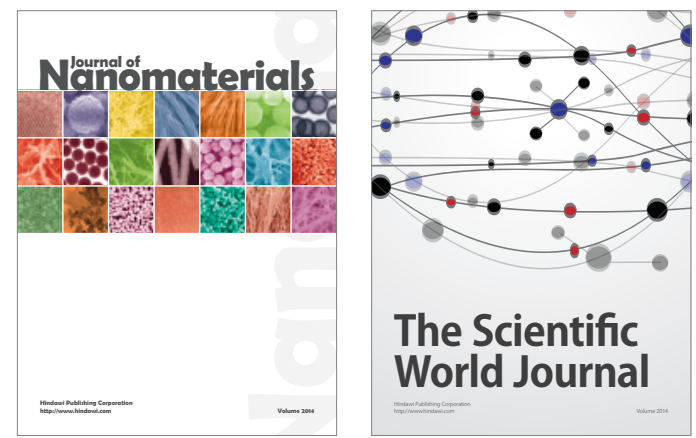

The Scientific World Journal
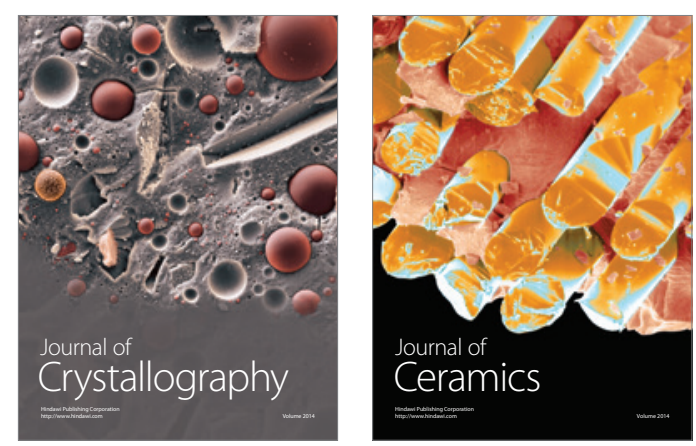
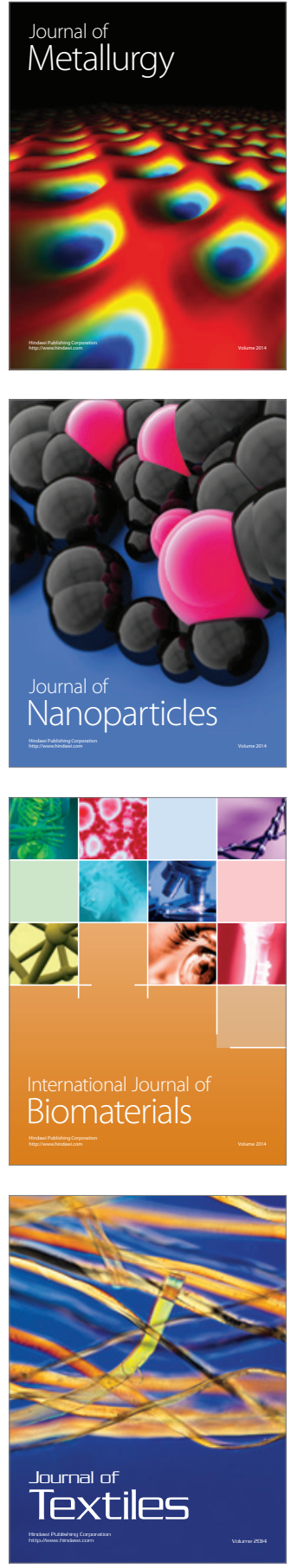